\title{
Historical Paper
}

Stereotactic

and Functional

Neurosurgery
Stereotact Funct Neurosurg 2015;93:42-49

DOI: $10.1159 / 000366490$
Received: March 31, 2014

Accepted after revision: August 7, 2014 Published online: January 31, 2015

\section{Remarks upon the Term Stereotaxy: A Linguistic and Historical Note}

\author{
Peter Grunert Sr. Doerthe Keiner Joachim Oertel \\ Neurosurgical Department, University of Saarland, Homburg/Saar, Germany
}

\section{Key Words}

Stereotaxy · Historical development $\cdot$ Philological

explanation

\begin{abstract}
The correct explanation of the term 'stereotaxy' is linguistically not self-evident because the Greek term stereon means not spatial but 'hard' or 'solid'. The aim of our study was to clarify the term stereotaxy historically and linguistically. We carried out our study by reviewing the neurosurgical and ancient Greek literature. The term stereotaxy is composed of two ancient Greek words: stereon and taxis. Stereon was used in particular as a technical term for geometrical solids in Greek mathematics. This term can be traced back to Platon and Euclid in the 4th and 3rd century BC, respectively. Only in this sense of the word does stereon in stereotaxy actually mean 'spatial' or '3-dimensional'. Taxis is derived from the verb tattein (tátteıv) with the meaning 'to position'. The terms 'stereotaxis' and 'stereotaxic apparatus' were introduced by Clarke and Horsley in 1908 to denote a method for the precise positioning of electrodes into the deep cerebellar nuclei of apes. The target in space was defined by 3 distances in relation to 3 orthogonal planes. Although this con-
\end{abstract}

cept corresponded exactly to $x$-, $y$ - and z-coordinates in a cartesian coordinate system, Clarke never used the concept of coordinates. The intuitive explanation of the term stereotaxy as spatial positioning is correct, but linguistically more complex than would be expected.

(c) 2015 S. Karger AG, Basel

\section{Linguistic Explanation of the Term 'Stereotaxy'}

The term 'stereotaxy' is usually explained as being composed of the two Greek words stereon ( $\sigma \tau \varepsilon \rho \varepsilon$ òv), in the meaning of '3-dimensional' or 'spatial', and taxis ( $\tau \alpha \dot{\xi} \xi \sigma)$, in the meaning of 'placing', 'positioning'. In this interpretation, stereotaxy would be a method for the precise 3-dimensional positioning of cannulas or electrodes into the brain.

What, then, is the philological problem? The problem is that the adjective stereon in ancient Greek means firm, compact, hard, solid, and stable, but not spatial or 3-dimensional. For space, the Greek used the term choron ( $\chi \tilde{\omega} \rho \circ v)$, and for 2-dimensional they used second exten-

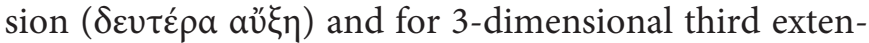

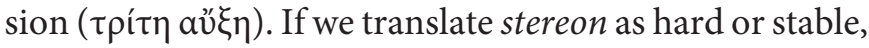

\section{KARGER 125}

(c) 2015 S. Karger AG, Base

1011-6125/15/0931-0042\$39.50/0
Prof. Peter Grunert Sr.

Department of Neurosurgery, University of Saarland

Kirrbergerstrasse 100/Building 90.0

DE-66424 Homburg/Saar (Germany)

E-Mail peter.grunert@uks.eu 


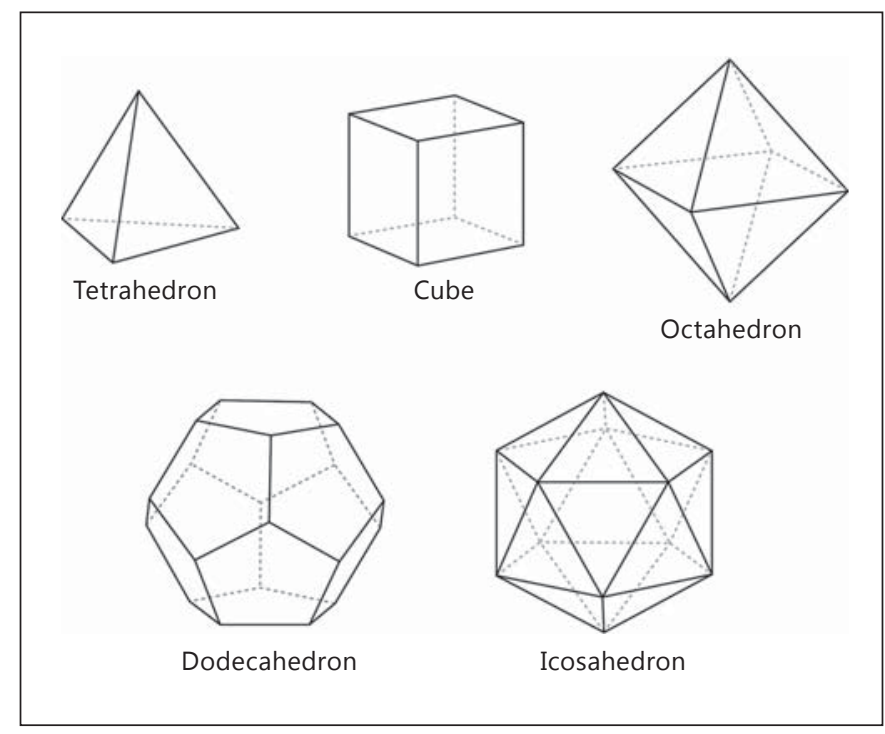

Fig. 1. The 5 Platonic solids. Symmetrical regular solids. Each 3-dimensional figure is composed of planes in the form of either equilateral triangles or squares or regular pentagons. Their names are derived from the number of their surfaces: tetrahedron (4 triangles), cube or hexahedron (6 squares), octahedron (8 triangles), dodecahedron (12 pentagons), icosahedron (20 triangles). Mathematically, the number of these objects is limited to 5 .

the term stereotaxy could refer either to the stable fixation of the frame on the head or to the stable cartesian coordinate system in relation to which every target point is calculated, or alternatively to the stable and precise positioning of electrodes into the deep brain structures. On the other hand, we use stereon today in compound technical terms such as stereometry, stereophony or stereoscopy, where stereos clearly does not mean hard or compact but spatial or 3-dimensional.

The answer to this problem is that in ancient Greek mathematics stereon ( $\sigma \tau \varepsilon \rho \varepsilon v^{2}$ ) was also used as a technical term to denote 3-dimensional geometrical solids such as pyramids, cubes, cones, polyhedrons or the Platonic solids. In a very technical sense it also referred to the third root of an integer $[1,2]$. This specific mathematical meaning of stereon as a geometrical solid has later become generalized in our scientific literature to signify spatial or 3-dimensional in general.

Stereon in the geometrical sense of the word can be traced back to Platon (428-348 BC) and Euclid (360-280 $\mathrm{BC}$ ). Platon used the word stereon in his dialogues Theaitetos [3] and Politeia (i.e. The Republic) [4]. Theaitetos is a dialogue on the relevance of scientific knowledge. Theaitetos (415-369 BC), a well-known mathematician of the

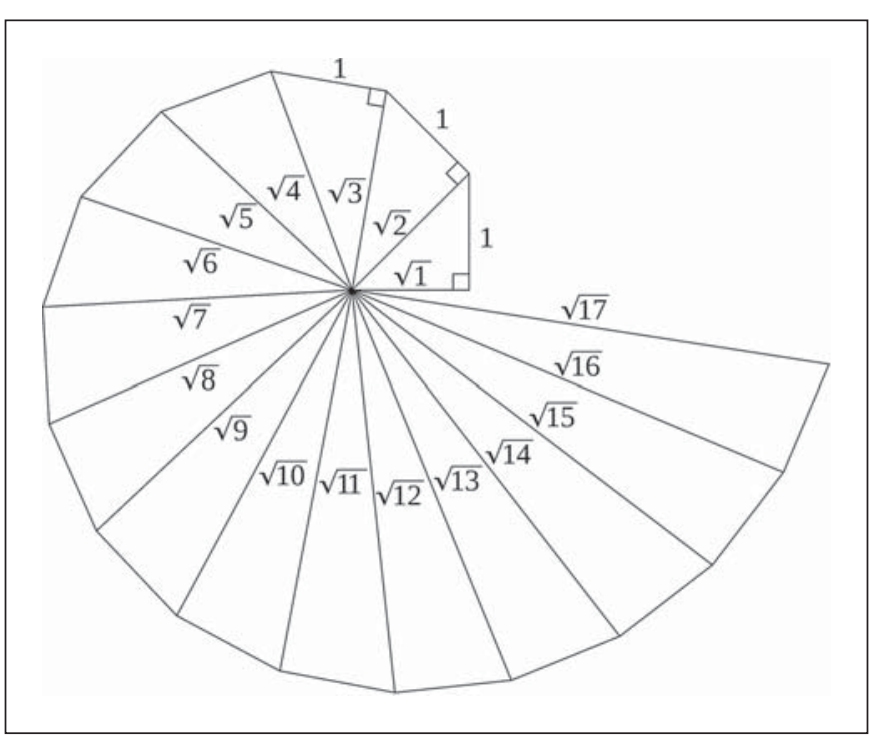

Fig. 2. The snail or spiral of Theodoros. Geometrical construction of square roots from 1 to 17 as hypotenuses of right triangles evolving by continuous adding of a right triangle with leg 1 . With permission from PBroks13@en.wikipedia.

time who became known for his construction of the 5 Platonic solids (fig. 1), illustrated Socrates' scientific knowledge by means of the geometrical construction of the square roots from 1 to 17 . He used a method of his teacher Theodoros of Cyrene (465-399 BC), the so-called spiral or snake of Theodoros (fig. 2). Theaitetos generalized this result also for the third root of integers and said:

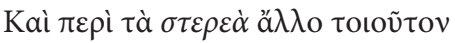

For solids (sterea) similar considerations are possible.

In his dialogue The Republic, Socrates discussed a scheme to teach geometry to the future elite of his ideal state. He proposed that, logically, the geometrical figures in the 2-dimensional plane needed to be studied first, then the solids in space and lastly the solids in motion, meaning astronomy. Verbatim, Socrates said:

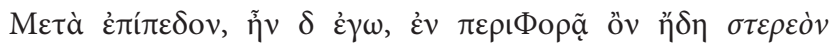

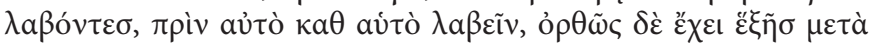

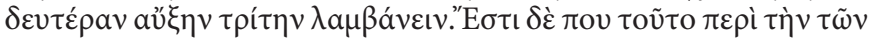

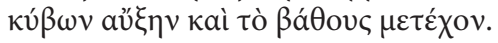

After the plane, I said, we investigated already solids (sterea) in motion, before we investigated them as they are; it would be correct to study step by step after the second dimension the third dimension. It is about the extension of cubes and objects having a depth. 
Fig. 3. First page of Euclid's The Elements. First printed edition, in Latin, of Euclid's The Elements from 1482, edited by Erhard Ratholt (Venice), based on the handwritten edition of Campanus of Novara from 1260. With permission for reproduction from the Bavarian State Library, Munich, Rar. 292.

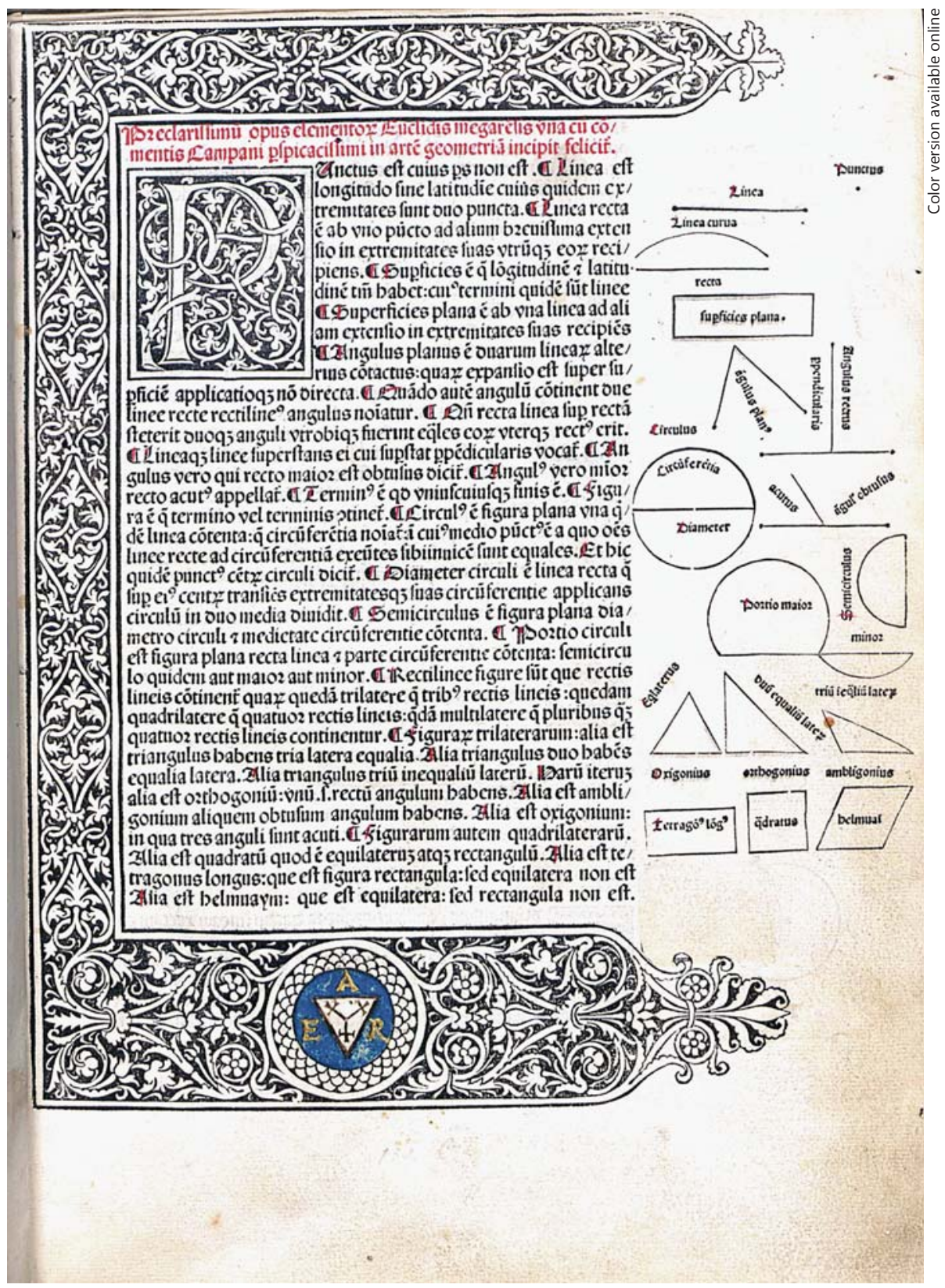

The precise ancient mathematical definition of the term stereon can be found about 100 years later in the encyclopaedic mathematical work of Euclid of Alexandria (around 360-280 BC). His book The Elements (Stoicheia or $\sigma \tau$ тo $\chi \varepsilon \tilde{\varepsilon} \alpha$ ) [5], laid the foundation for axiomatic geometry where all geometrical theorems and constructions have to be proven and have to refer strictly only to terms and axioms defined beforehand (fig. 3).

At the beginning of book XI (fig. 4), stereon, or corpus in Latin, is defined as:
Corpus est quod longitudinem et latitudinem et altitudinem habet cuius termini sunt superficies.

A solid is an object with a longitude, a latitude and an altitude, whose borders are planes.

The second half of the word stereotaxy, namely Greek taxis, is derived from the ancient Greek verb tattein ( $\tau$ á $\tau \tau \varepsilon เ v$ ), meaning 'to place' or 'to position'. In accordance with Greek grammar, the double $t$ changes to $\mathrm{x}$ when this word is used as a noun or adjective, thus becoming taxis and taxic, respectively, meaning place- 
Fig. 4. Definition of a solid. First page of Euclid's The Elements, book XI, from the edition of 1482 by Erhart Ratholt (Venice). With permission for reproduction from the Bavarian State Library, Munich, Rar. 292.

Fig. 5. Definition of a target point in space in relation to 3 orthogonal planes.

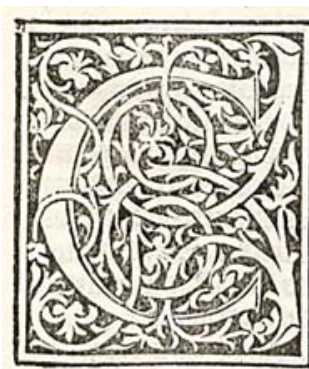

D.pus eft qölongitudinem $z$ latítudunem $\tau$ altitndinc babet cui? termini fint fupfictes Linca crecta iunza fupficié é que cü linzzulis fibi pterminahibus lincis in ca fuppicic expā fis angulos rectos facit.linea aüt bec finp?a cá luperficié perpendicularis efléc rad eãde astbogonaliter unfiftere oicitur.

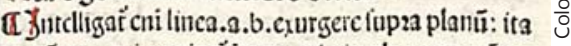
q pǘctus.a.imagincti i scre z.b.in plano r a pǘcto b.oucant plures linec in eodem plano ut.b.c. b.d. $\tau$ uotlib; alie. Si igir ita fucrit $\varphi^{\text {linea }}$ a.b.cū linca

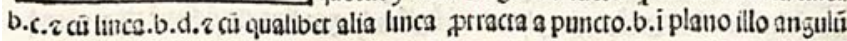

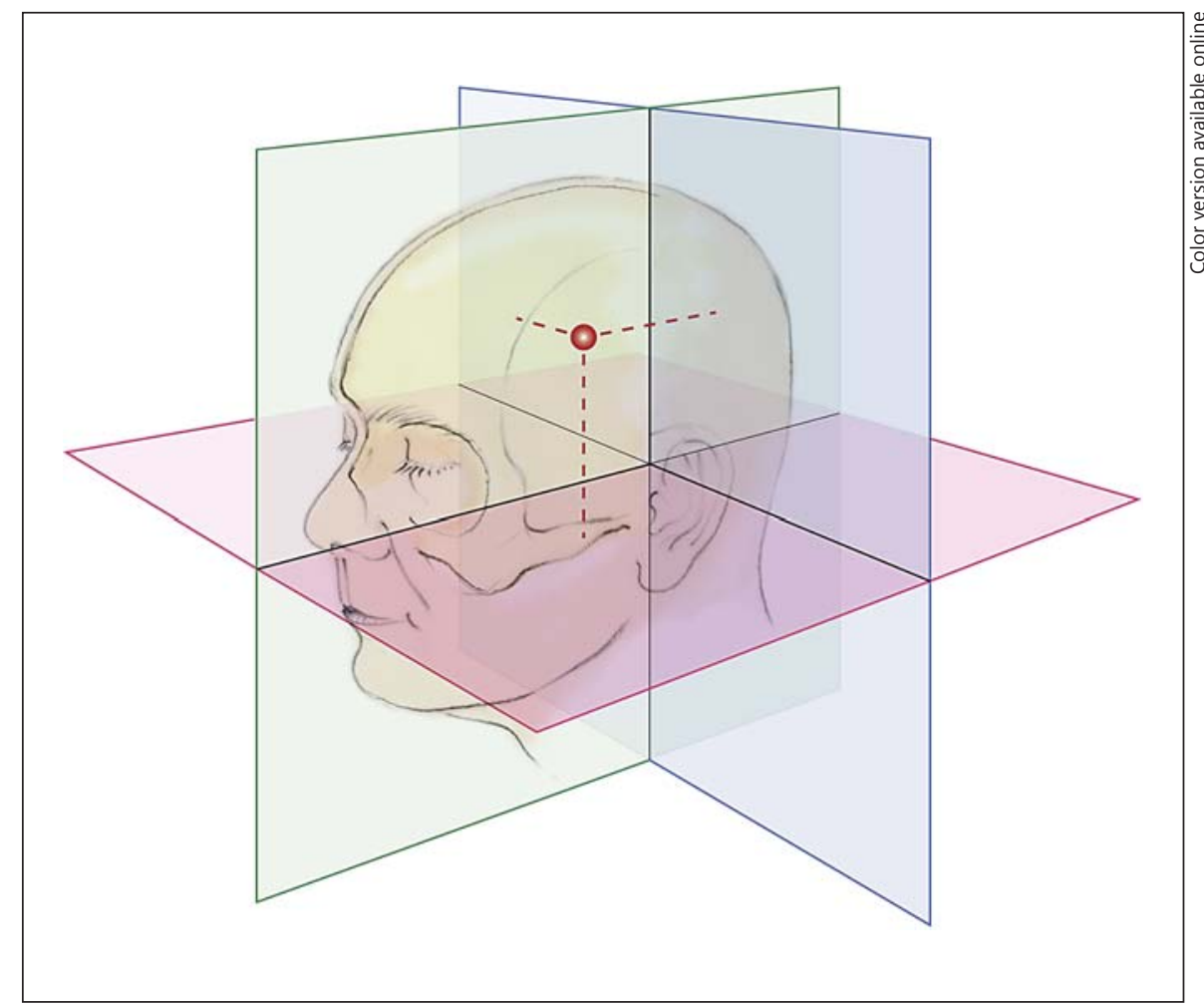

ment or positioning. The correct adjective is therefore stereotaxic and not stereotactic as commonly used. Previously, there has been a debate whether the adjective 'stereotactic' might refer to Latin tactus, the past perfect tense of tangere, meaning 'to be touched'. However, the essence of the stereotaxic procedure speaks very much in favour of positioning rather than touching. Horsley and Clarke, who introduced this term, spoke also of stereotaxis and of a stereotaxic rather than a stereotactic apparatus.

\section{History of the Term Stereotaxy}

The term stereotaxy can be traced back to the publications of the neurosurgeon Victor Horsley (1857-1916) and the surgeon, anatomist and physiologist Robert Henry Clarke (1850-1926) who developed and applied this method since 1903 in the laboratory of pathological chemistry at the University College in London. In their preliminary publication in the British Medical Journal in 1906 [6], they described this method without using a special term for it. Later, they used the terms stereotaxy and stereotaxic apparatus for the first time in their main work 
Fig. 6. The stereotaxic apparatus of Clarke and Horsley 1908. With permission for the reproduction of pages 64 and 67 from Horsley and Clarke [7]. a View from above.

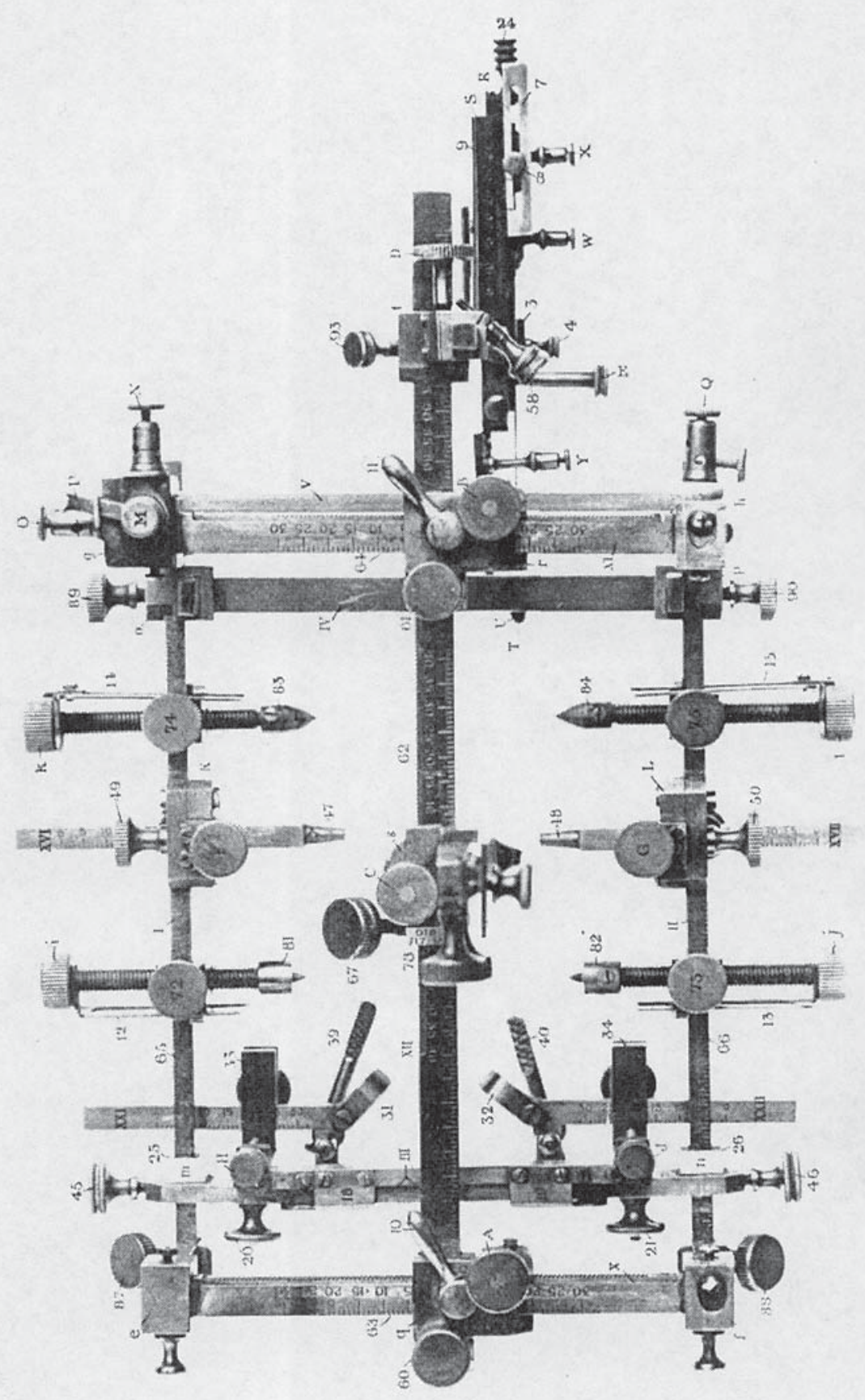

The structure and function of cerebellum investigated by a new method', which was published in Brain in 1908 [7]. Horsley and Clarke studied the contribution of the cerebellum and the deep cerebellar nuclei to movement. They wanted to accurately place electrodes into the deep cere- bellar nuclei of apes for the purpose of stimulation and for creating precise and circumscribed lesions.

To achieve this, it was necessary to define a target in space independently of the approach, the thickness of the integument above the skull and without using a projection 
Fig. 6. The stereotaxic apparatus of Clarke and Horsley 1908. With permission for the reproduction of pages 64 and 67 from Horsley and Clarke [7]. b Oblique view.

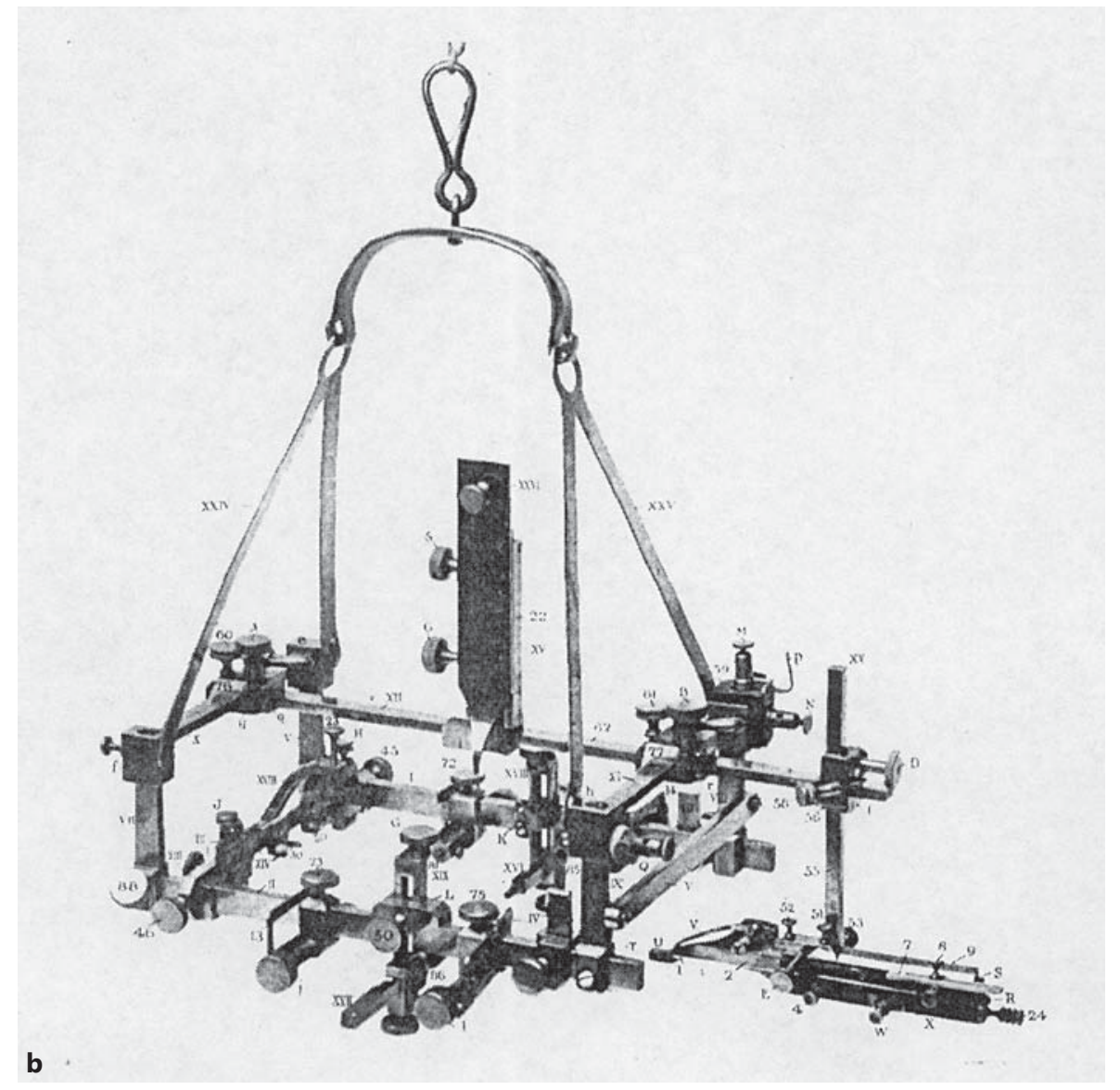

to the cortical surface. Clarke had the idea of defining the target point in space by 3 distances in relation to 3 orthogonal planes. The position of these planes was based on external anatomical landmarks. The horizontal or basal zero plane ran along the inferior orbits of the maxilla through both external acoustic meatus, the frontal zero plane was orthogonal to the horizontal plane running through both acoustic meatus, and the sagittal zero plane was perpendicular to both planes dividing the head into two equal halves (fig. 5). Thus, the space was divided by these 3 planes into 8 subspaces, 4 above and 4 below the horizontal zero plane. The target was located in one of the 8 subspaces and was defined by the 3 distances to each plane (fig. 5). This was a long-winded formulation for the concept of $x-$, $y$ and $\mathrm{z}$-coordinates in a cartesian coordinate system. Clarke, however, was not a mathematician and never used the simple concept of coordinates in his publication.

Clarke also created an ape atlas by cutting the frozen head of an ape parallel to the 3 orthogonal zero planes in 1-mm steps. To secure the identification of the section, 2 ivory needles were introduced perpendicular to each zero plane before cutting. To measure the distances of the target to each zero plane, the appropriate section with the target was selected and a translucent glass plate with a millimetre scale was laid over the section and aligned in relation to the 2 ivory reference points. Thus, distances in 2 directions could be read off directly. The 3 distances of the target could thus be obtained from an appropriate sagittal section measuring the distances to the horizontal and frontal zero planes, and in a frontal section measuring the distance to the sagittal zero plane.

Clarke also developed a frame for fixating the head (fig. 6). This construction allowed to move a holder along the 3 orthogonal planes for setting the distances. The frame was additionally equipped with a carrier for holding and precise introduction of the electrode.

Since Clarke, the definition of the target in space, the stereotaxic atlas and the stereotaxic frame have constituted the basic principles of stereotaxy which have also been valid for human application up to now. 
Fig. 7. Encephalometer. Zernov's publication entitled 'Encefalometer. A device for localizing parts of the brain in living humans'. Moscow, 1892. With permission for the reproduction of page 408 from Kandel and Shavinsky [11].

\section{ЭНЦЕФАЛОМЕТРЪ.}

\section{Прнооръ для опредыленія положенія частей мовг у жп-} вого человька.

Проњ. Москопекаго Уиипюреиттп

ㄱ). $\mathfrak{H}^{\text {Seproba. }}$

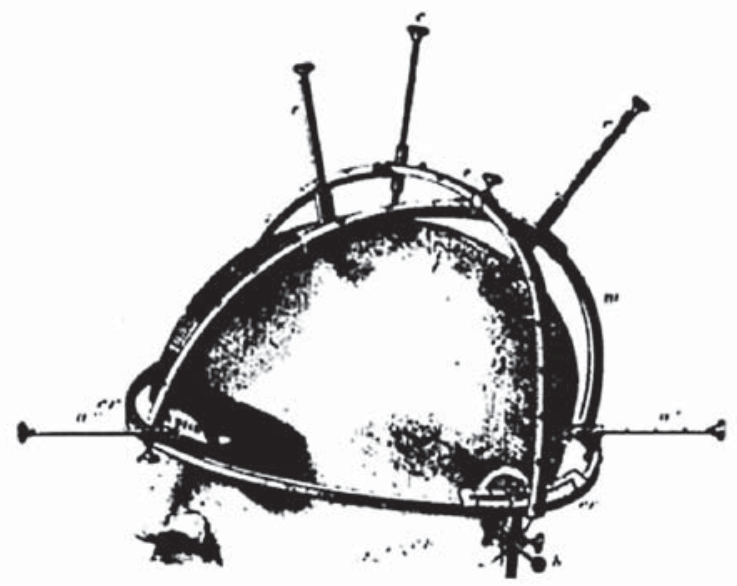

Нзготовпень фирмою „.Ө. Швабе“ вь Mockst.

II () $(:$ \& 13 i

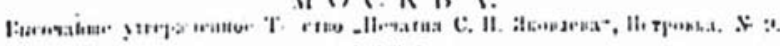
1892
Regrettably, Horsley died in 1916 during World War I in the Middle East. Clarke had also developed the idea to apply the stereotaxic instrument to humans, but his collaboration with Horsley ceased after their main publication and he was only able to further improve his instrument from the technical point of view and thereafter to patent it in 1914. Retrospectively, it has to be conceded that Clarke's calculation based solely on external landmarks of the skull was accurate enough only for apes but, due to their greater interindividual variability, not for humans. For humans, additional intracerebral reference points were necessary, which were not developed until 1947.

Clarke was not the first to develop a device for localizing intracranial structures. In Moscow, the Russian anatomist Zernov developed and applied a frame for localizing brain structures as early as 1889 . He called this device an encephalometer. It consisted of a frame and a pointer mounted on an arc system (fig. 7). The idea was to localize superficial lesions or eloquent cortical areas in dependence on a dome via a geodesic coordinate system with degrees of longitude and latitude (fig. 8).

However, the early Russian stereotaxic school around Zernov, Altuchov and Rossolimo published their work mostly in Russian, and in their publications they never used the term stereotaxy or a corresponding Russian translation of this word [8-11].

\section{Acknowledgement}

The authors thank Stefan Kindel for the drawings and composition of the illustrations and figures.
Grunert Sr./Keiner/Oertel 
Fig. 8. Definition of the target in a geodesic coordinate system with degrees of longitude and latitude. Mathematically correctly applicable only for targets on the surface of a sphere.

\section{References}

- Neuschwander E: Die stereometrischen Bücher der Elemente Euklids (The Stereometric Books of Euclid's The Elements). Arch Hist Exact Sci 1974;14:91-125.

2 Wussing H: Vorlesung zur Geschichte der Mathematik (Lecture on the History of Mathematics). Frankfurt, Harri Deutsch, 2008, pp 56-59.

3 Hülser K (ed): Platon: Theaitetos. Platonis opera omnia. Association Guillaume Budé. Frankfurt am Main, Insel-Verlag, 1991, vol 8, p 53c.

4 Hülser K (ed): Platon: Politeia (The Republic). Platonis opera omnia. Association Guillaume Budé. Frankfurt am Main, Insel Verlag, 1991, vol. 5, p 528b.

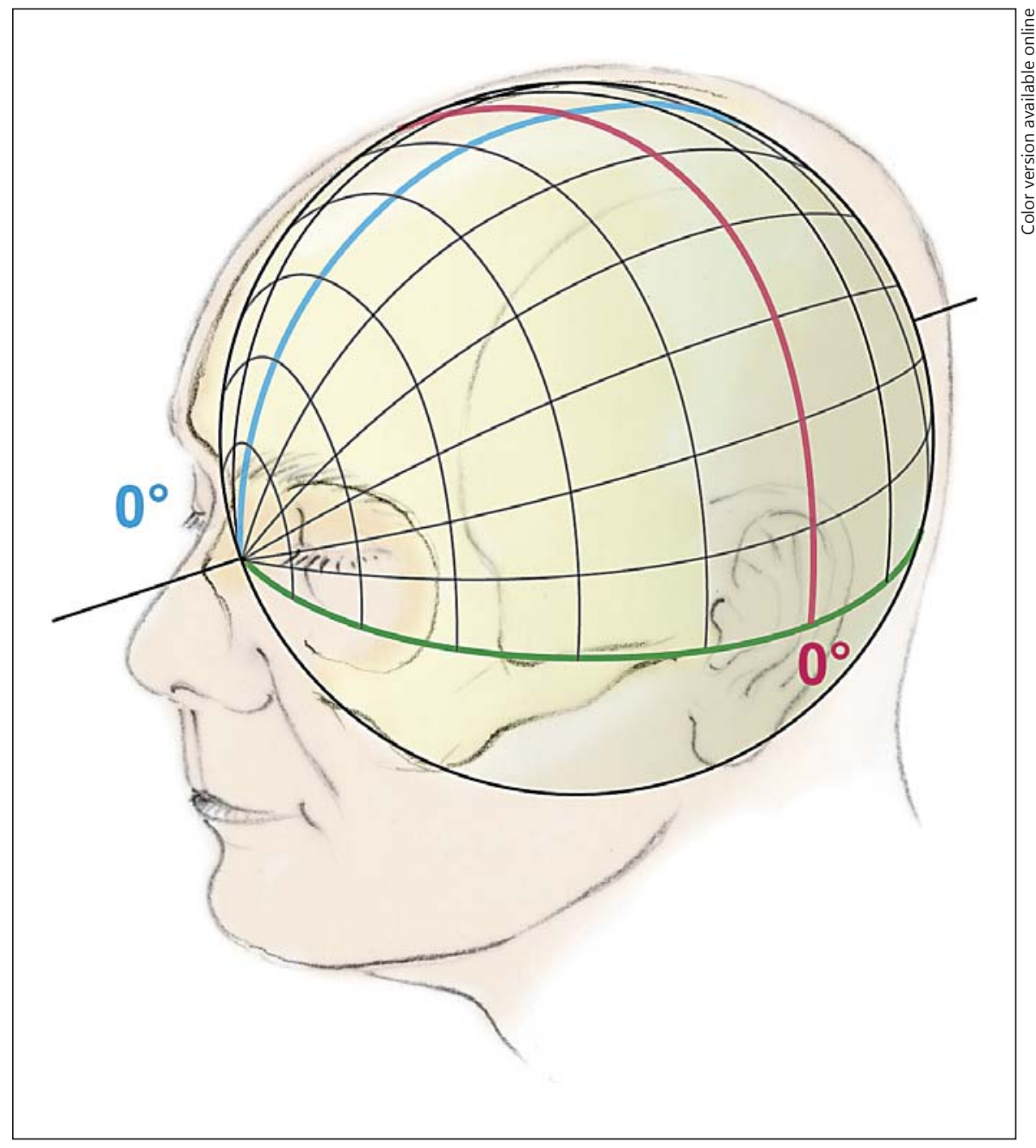

5 Heiberg JL, Menge H (eds): Euclid: Stoicheia (The Elements). Euclidis opera omnia. Leipzig, Teubner, 1883-1916, pp XI-XIII.

6 Clarke RH, Horsley V: On a method investigating the deep ganglia and tracts of the central nervous system (cerebellum). Br Med J 1906;ii:1799-1800.

7 Horsley V, Clarke RH: The structure and functions of cerebellum investigated by a new method. Brain 1908;31:45-124.

8 Zernov D: Entsefalometr-ustroistvo dlya opredleniya polozheniya mozgovikh structur u zhivogo choloveka. Predvaritel'noe soobshenie. (Encephalometer - a device for determination of localizing cerebral structures in a living man. A preliminary communication). Trudi fiziko-meditsinskogo obshestva moskovskogo universiteta 1889;2:70-80.
9 Altuchov N: Entsefalometriya mozga choloveka $\mathrm{v}$ otnoshenii $\mathrm{k}$ polu, vo zrastu i chrepnomu ukazateyu. (Encephalometry of the human brain in connection with sex, age and cranial index). Isdatelstvo moskovskogo universiteta Moskva, 1891.

10 Rossolimo GI: Mozgovoi topograf (Brain topographer). Zhurnal Neuropathologii I Psichatrii imeni Korsakova/J Neuropath Psych Korsakow 1907;7:640-644.

11 Kandel EI, Shavinsky YV: Stereotaxic apparatus and operations in Russia in the 19th century. J Neurosurg 1972;37:407-411. 